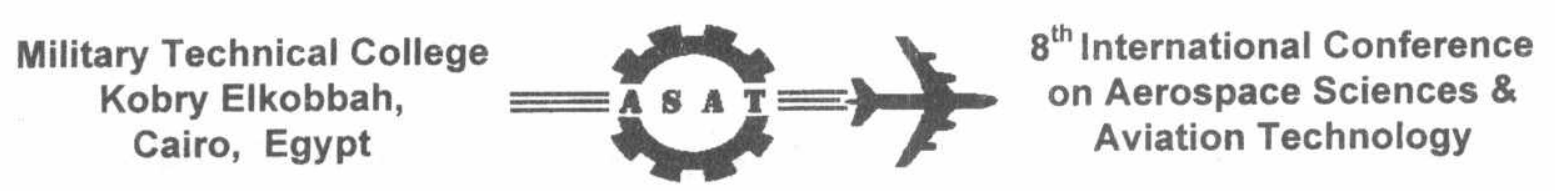

\title{
ALUMINUM METAL MATRIX COMPOSITES IN AEROSPACE APPLICATIONS
}

\author{
B. M. RABEEH ${ }^{*}$, M. M. MOUSSA ${ }^{+}$, M. Y. MOHAMED ${ }^{+}$ \\ AND M. A. EL- HADDAD ${ }^{+}$
}

\begin{abstract}
The aerospace industry's constant desire to enhance the performance of commercial and military aircrafts is continually driving the development of improved high-performance structural materials. In recent years, Metal-matrix composites (MMC) have emerged as a promising class of materials. Especially, Aluminum composites with their unique thermal properties have enormous space and avionics prospects. Al-matrix composites have the potential of achieving significant weight and cost savings on aircraft structures. In this paper, the fabrication and properties of the Al-matrix composites and their scopes in aerospace industries will be reviewed in details. Besides, recently Hot Isostatic Pressed (HIPed) Al-matrix composites reinforced with steel fibers and its evaluating parameters will be discussed with microstructure changes and mechanical behavior.
\end{abstract}

\section{INTRODUCTION}

The key to the successful development of next-generation aerospace propulsion and power systems is advanced materials. These materials must not only be resistant to high temperatures, but they must also provide significant improvements in weight specific mechanical and/or thermal properties. Metal-matrix composites (MMCs) are one such class of materials, which are certain to play a significant role in the development of future aerospace components. MMCs are particularly interesting for space structures applications because of their excellent specific mechanical properties, high thermal and electrical conductivity, low coefficient of thermal expansion and the absence of outgassing.

Metal-matrix composites, in general, consists of at-least two components, one is the metal matrix and the second component is a reinforcement. The matrix is defined as a metal in all cases, but a pure metal is rarely used as the matrix, it is generally an alloy. In the production of the composite, the matrix and the reinforcement are mixed together. Aluminum is the most attractive non-ferrous matrix material used particularly in the aerospace industry where weight of structural components is crucial. The unique thermal properties of aluminum composites, such as metallic conductivity with coefficients of expansion that can be tailored down to zero, add to their prospects in aerospace and avionics. Different classifications of aluminum based metal matrix are included with

\footnotetext{
* Department of Materials Science and Engineering, MTC, Cairo.

+ Department of Automotive Engineering, MTC, Cairo.
} 
recently applicable processing technique as Hot Isostatic Pressing (HIPing) of Aluminum foils with steel fibers. Parameters required for investigating the optimal results of HIPing are also obtained with the effects of temperature and holding time.

\section{CLASSIFICATION OF ALUMINUM BASED MMCS}

Several types of aluminum based MMCs have been developed for applications in aerospace. The main reasons for adding reinforcements to aluminum and aluminum alloys are to increase the strength, stiffness or wear resistance but this is usually achieved at the expense of other properties such as ductility. The reinforcements can be in the form of continuous fibers (e.g. carbon, $S_{i} C$, or steel). ), Discontinuous fibers, particulates or whiskers. The last three are usually inorganic (ceramic) materials such as alumina, silicon carbide or silicon nitride.

The choice of steel fibers as the reinforcement in aluminum composites is primarily due to its excellent combination of mechanical properties, availability and cost. Besides, some other important properties of the Al/steel fiber composites as;

(1) Thermal expansion coefficient can be tailored to adjoining components by adjusting the volume fraction of reinforcement.

(2) The composite has high dimensional stability or resistance to deformation under load known as creep.

(3) The continuous the reinforcement fibers the greater the strength and creep resistance.

\section{FABRICATION OF AL BASED MMCS}

The fabrication of metal matrix materials may be considered in two stages: the fabrication of the composite material from base metal and fiber reinforcement, and the subsequent fabrication of laminates from the composite material. In some cases, the two steps occur simultaneously depending on the final material product desired and the method of fabrication used in the process. Sheet rolling can import directional strength and cross rolling makes properties more uniform. Super plastically formed horseshoes have been used where lightness and wear are a competitive edge. [1-6]

The choice of methods used to fabricate a composite material depends on the mechanical and chemical properties of the fiber and matrix, the fiber length and size, the fiber packing, and the desired fiber configuration. Furthermore, it is necessary to know the thermodynamics and kinematics of possible fiber matrix reactions and service temperatures to which the composites are subjected. Short overviews of some of the methods used to fabricate aluminum matrix composites (AMCs) are discussed below [6].

\section{(1) SOLID STATE PROCESSING}

Incorporation of reinforcing fibers in the metal matrix by solid state bonding is achieved through diffusion bonding at high pressures and elevated temperatures. However, the degree of diffusion must be limited or unwanted brittle phases may be grown at the 
interfaces [1-3]. One means of limiting the diffusion time is by extrusion of a sandwich of fibers and matrix through a die. Hot rolling may also be used but, in this case, the deformation of the matrix must be limited to minimize the displacement of the reinforcing fibers to avoid damage. Elevated temperatures are used to facilitate matrix flow but care must be taken to avoid excessive heating that would promote chemical attack of the fibers. A disadvantage of this process is the need for very clean surfaces before bonding is attempted. This usually requires precleaning of the constituent materials and operation in a vacuum. B/AI, Borsic/Al, or steel/Al composites are consolidated using this method [5]. Hot Isostatic Pressing (HIP), the simultaneous application of heat and high-pressure, has become a standard production process in many industries. In the HIP unit a high temperature furnace is enclosed in a pressure vessel. Work pieces are heated and an inert gas, generally argon, applies uniform pressure. The temperature, pressure and process time are all controlled to achieve the optimum material properties. HIP processing incorporated as an integral part of the manufacturing process reduces scrap and improves yield. HIP frequently allows replacement of wrought components by castings. It can reduce quality assurance requirements by improving material properties and reducing property scatter. Often, the savings on radiographic costs will cover the costs of HIP. Besides, it maximizes material utilization by improving material properties. HIP parameters can be established to minimize subsequent heat treatment requirements [2-5].

\section{(2) LIQUID STATE PROCESSING}

In attempting to bond the metal matrix to the fibers, it is desirable to have the liquid from the matrix flow into the interstices of the fiber tows to provide complete coating of the fibers. Such a process, utilizing a dip bath, can facilitate production considerably and is currently used by the industry to produce wire pre-forms. The disparity between the need to wet the fibers and the avoidance of excessive chemical reaction between the fiber and the matrix necessitates the pre-treatment of fibers by coating them with a compound of titanium diboride. The coated fibers are then drawn through a bath of molten aluminum in a continuous process. Liquid infiltration of molten aluminum into the fiber tow provides a means of separating the fibers as well as providing a bonding interface between matrix and fiber. Fiber coating such as titanium diboride aid wetting as well as protecting the fiber from chemical attack at elevated temperature [3-5].

\section{(3) POWDER METALLURGY}

Powder Metallurgy involves the blending of rapidly solidified powders with particulates, platelets or whiskers, through a series of steps. The sequence of steps include [4-6]:

(1) Sieving of rapidly solidified particles

(2) Blending of the particles with the reinforcement phase(s)

(3) Compressing the reinforcement and the matrix mixture to about 75 percent density

(4) Degassing and final consolidation by extrusion, forging, rolling or any other hot working method. 


\section{(4) PHYSICAL VAPOR PROCESSING (PVD)}

This type of processing represents a range of methods including electron beam evaporation, Magnetron sputtering and electro-deposition methods where composites are fabricated by deposition of successive layers of matrix being deposited on fiber reinforcements. Physical Vapor Deposition (PVD) techniques involve much less heating of the fibers than liquid infiltration. The surface temperatures are typically maintained below $200 \mathrm{C}$. This technique is widely used to produce Gr/Al composite [5-11].

\section{(5) DIRECT PROCESSING/SPRAY DEPOSITION}

In this method, finely divided molten droplets allowed to impinge on a substance before they completely solidify allowing direct formation of near net shapes rather than having to go through the intermediate steps of $\mathrm{P} / \mathrm{M}$. One such commercial process is the Co-spray Process [12].

Though this process does not exhibit solidification rates as high as the rapid solidification, it offers two advantages: direct production of preform shapes and direct inclusion of reinforcing materials into the parent matrix ("Co-spray deposition"). Billet and disk preforms are being evaluated using materials such as aluminum -matrix composites (AMCs) and superalloys. Direct production/Spray deposition allows effective use of material and elimination of various processing steps [12-14].

\section{EXPERIMENTAL WORK:}

\section{PRODUCTION OF AL-MMC BY HOT PRESSING}

Rolled foil of Aluminum ( $500 \mu \mathrm{m}$ thickness) are used with steel fibers ( $300 \mu \mathrm{m}$ diameters) for composite processing. A ten-ton press is used for pressing. Aluminum metal matrix composite is produced by foil-fiber-foil technique symmetrical from the center in a zero direction and five plies $[0]_{5}$. Hot Pressing parameters were investigated to test different samples at $620^{\circ} \mathrm{C}, 630^{\circ} \mathrm{C}$ and $640^{\circ} \mathrm{C}$ for one, two or three hours. Temperature effects, with holding times were investigated to see if they satisfy the requirement for HIPing processing.

\section{RESULTS AND DISCUSSIONS}

\section{1- MICROSTRUCTURAL ANALYSIS}

Scanning Electron Microscopy images were obtained for finally polished and etched AlMMCs samples. The effect of temperature was investigated to be test at $620^{\circ} \mathrm{C}, 630^{\circ} \mathrm{C}$ and $640^{\circ} \mathrm{C}$ for all samples Figure 1,2 and 3 respectively. A new generated interface was obtained as consequences of diffusion process at different holding time. The effect of holding time was investigated for each temperature level at three different times of 1, 2 or three hours as clear in Figures 1,2 or 3 at a, b, c respectively.

However, Al composite processed at $620^{\circ} \mathrm{C}$ revealed a clear image with a localized interface, there were little debonding and delamination between foil lay-up (Fig. 1a). 
Figure $1 \mathrm{~b}$ and $\mathrm{c}$ reveal scanning electron microscopy of aluminum metal matrix composite sample with steel fibers produced by Hot Pressing at $620^{\circ} \mathrm{C}$ for two and three hours. A clear debonding and localized interface were the dominant evidence at this level.

On the contrary, delamination of Al-foils was controlled at $630^{\circ} \mathrm{C}$ and different holding times, and a clear continuous localized interface established after one hour holding time (Fig. 2a). The effect of holding time revealed a high rate of diffusion processing between steel fiber and aluminum matrix. A continuous coarsened interface was obtained at $630^{\circ} \mathrm{C}$ for two hours holding time (Fig. 2b), while a highly diffused branched interface with clear cracking and branching was established at $630^{\circ} \mathrm{C}$ for three hours holding time (Fig. 2C).

A clear thin continuous and uniform interface was established at $640^{\circ} \mathrm{C}$ for one hour (Fig. 3a). While holding time effect was sharply induced coarsened interface at $640^{\circ} \mathrm{C}$ for two hours (Fig. 3b) and branched thick interface at $640^{\circ} \mathrm{C}$ for three hours (Fig. 3c). At this latest case, the fiber was almost consumed for diffusion.

\section{2- MECHANICAL BEHAVIOR}

Mechanical behavior and fracture surface analyses were established for another set of samples HIPed at the three different testing temperatures mentioned before. Another sample of monolithic aluminum matrix was HIPed and prepared using same technique for comparison. Fracture surface for finally established samples at $630^{\circ} \mathrm{C}$ with two hours and $640^{\circ} \mathrm{C}$ with one hours were obtained as clear in Figures $4 \mathrm{a}$ and b. Delamination and fiber pull-out were clear at $630^{\circ} \mathrm{C}$ with two hours (Fig. 4a). Ductile-dimpled fracture surface was the matrix criteria, while the interface revealed a cleavage fracture as a character of brittle material.

Stress-Strain analysis was investigated for $640^{\circ} \mathrm{C}$ samples HIPed at one, two, and three hours compared to that of a monolithic aluminum matrix as a reference sample Figure $5 a-$ $\mathrm{d}$ respectively. The interface has a highly induced effect on composite mechanical properties. Figure $5 \mathrm{~b}$, reveals high strength with ductility, while the effect of emerged brittle interface was established at Fig. $5 c$, d those showed low strength and ductility respectively. Figure $5 \mathrm{~b}-\mathrm{c}$ correlate the composite behavior and interface response that was clear in Figure 3a-c.

\section{CONCLUSIONS}

MMCs present some unique challenges for designers and materials engineers in the aerospace industry. From the materials stand point, they require an understanding of the interaction of two chemically different materials under extreme processing and operating conditions. From the design stand point, they require reconsideration in terms of component design, fabrication and quality assurance in order to obtain the most benefits from these materials. HIPing parameters were investigated for Al-MMC. Temperature effects and holding time effects were established. A continuous fine interface that obtained at $640^{\circ} \mathrm{C}$ for one hour holding time exhibit high strength and ductility compared to others. Stress-strain response established at $640^{\circ} \mathrm{C}$ for two or three hours holding time has lowest mechanical properties as a consequence of brittle branched interface. AlMMCs exhibit higher strength and ductility compared to monolithic Al-matrix. 


\section{References:}

1- W.Wei, "High Temperature MMCs for Aero-engines:Challenges and Potentials", Metals and Materials J., p:430-435, August-1992.

2- T.S.Srivatsan, I.A.Ibrahim, F.A.Mohammed and E.J.Lavernia, "Processing techniques for particulate-reinforced metal matrix composites", J. Materials Science, v:26, p:59655978, 1991.

3- D.Charles, "Addressing the challenge of aircraft component design and manufacture from MMCs", J. Aerospace Engg.(Proc. IMechE), p:1-13, 1992.

4- .Richard T.Holt,"Recent developments in aluminum technology for aerospace applications", Canadian Aeronautics and Space J., v:35, p:128-137, Sept-1989.

5- D.A.McCoy and D.J.Lloyd, Fabrication of graphite fiber reinforced aluminum", Canadian Aeronautics and Space J., v:33, p:11-17, March-1987.

6- A.N.Palazotta, Robert Ruh and George Watt, "Introduction to metal matrix composites in aerospace applications", J. Aerospace Engg., v:1, p:3-17, January-1988.

7- Michael E.Buck, "Advanced fibers for advanced composites", Advanced Materials and Processes", p:61-68, September-1.4^v

8- Alan L.Geiger and Michael Jackson, "Low-expansion MMCs boost avionics", Advanced Materials and Processes", p:23-30, July-1989.

9- Richard DeMeis, "New life for aluminum", Aerospace America, p:26-29, March-1989.

10- P.K.L_iaw,R.E.Shannon, W.G.Clark, W.C.Harrigan,H.Jeong and D.K.Hsu, "Determining material properties of metal -matrix composites by NDE", JOM, p:36-40, October-1992.

11- J.Wadsworth and F.H.Froes, "Developments in metallic materials for aerospace applications", JOM, p:12-19, May-1989.

12- J.Doychak, "Metal and intermetallic -matrix composites for aerospace propulsion and power systems", JOM, p:46-51, June-1992.

13- F.H.Froes, "Synthesis of metallic materials for demanding aerospace applications using powder metallurgy techniques"

14- Alan S. Brown, "Rivals take different paths to JSF", Engineering Notes, Aerospace America, August 1998. 


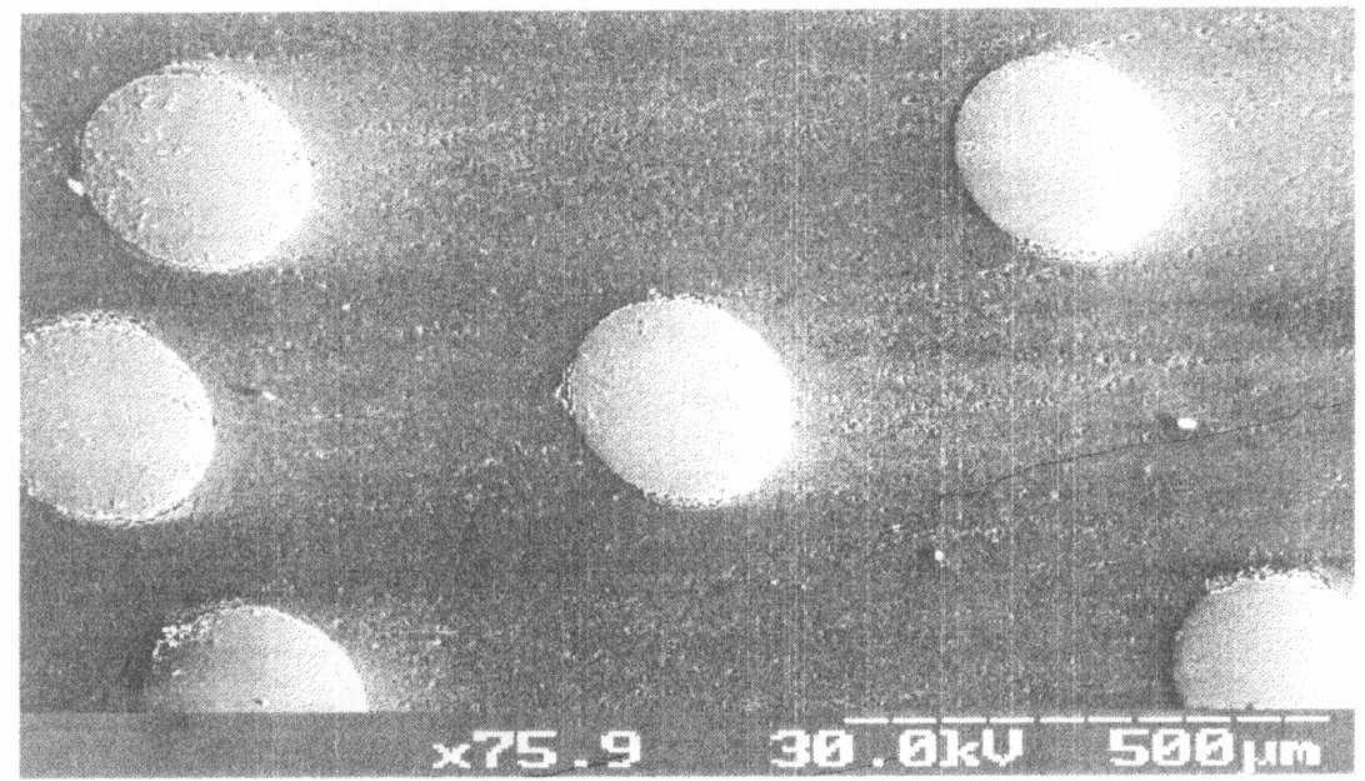

Figure 1a: Scanning Electron Microscopy of Aluminum Metal Matrix Composite Sample With Steel Fibers Produced by Hot Pressing at $620^{\circ} \mathrm{C}$ for one hour.

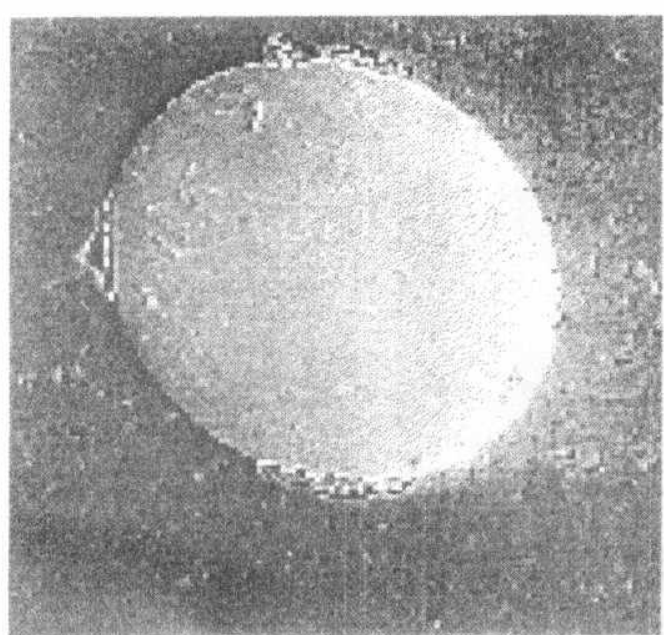

(b)

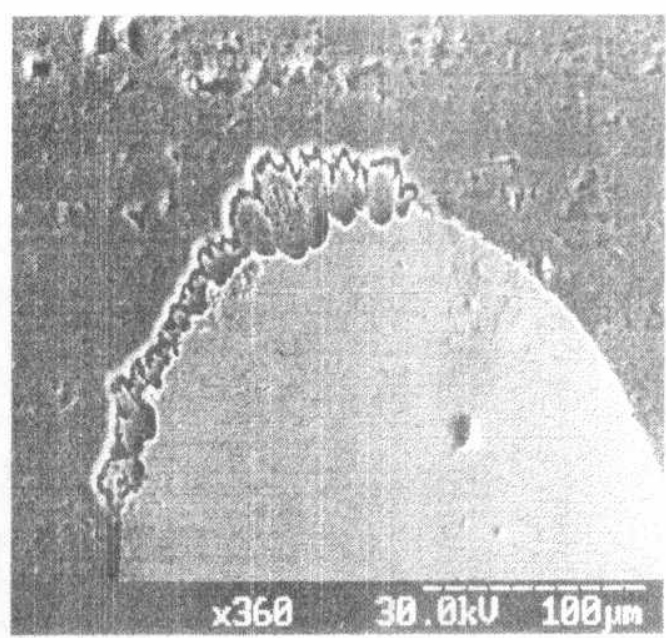

(c)

Figure 1b-c: Scanning Electron Microscopy of Aluminum Metal Matrix Composite Sample With Steel Fibers Produced by Hot Pressing at $620^{\circ} \mathrm{C}$ for: (b) Two hours (debonding at Foil/Fiber Interface); (c) Three hours (localized interface). 


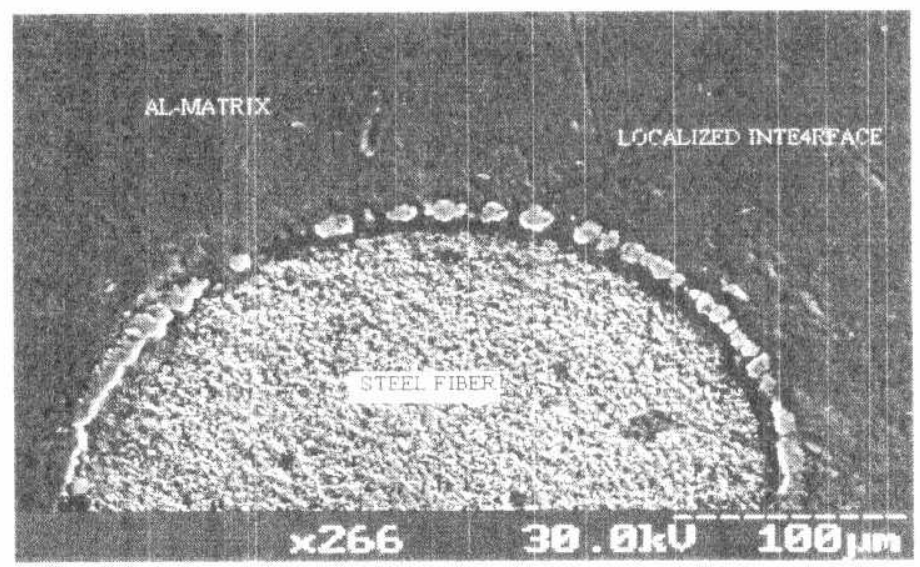

Figure 2a: Scarning Electron Microscopy of Aluminum Metal Matrix Composite Sample With Steel Fibers Produced by Hot Pressing at $630^{\circ} \mathrm{C}$ for one hour.

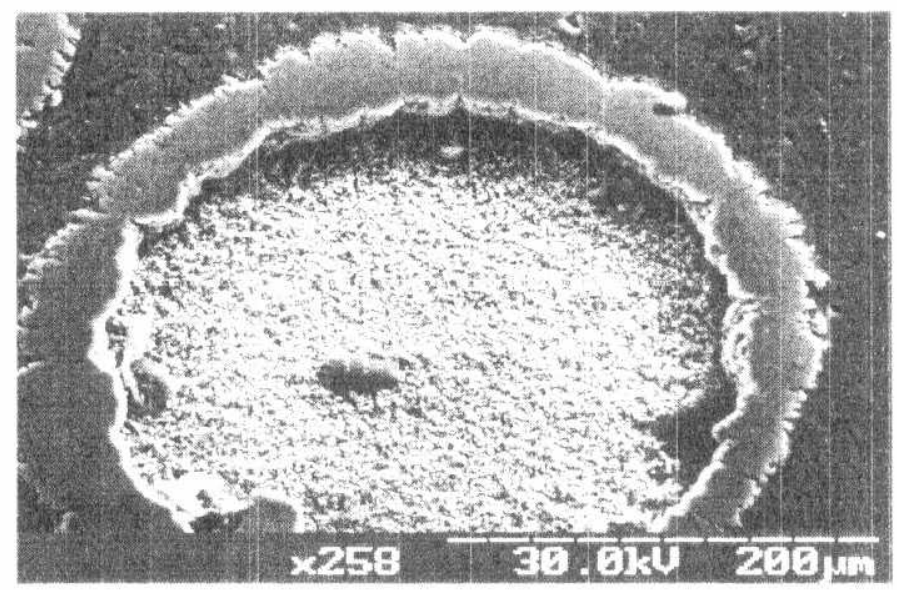

Figure 2b: Scarning Electron Microscopy of Aluminum Metal Matrix Composite Sample With Stizel Fibers Produced by Hot Pressing at $630^{\circ} \mathrm{C}$ for Two hours

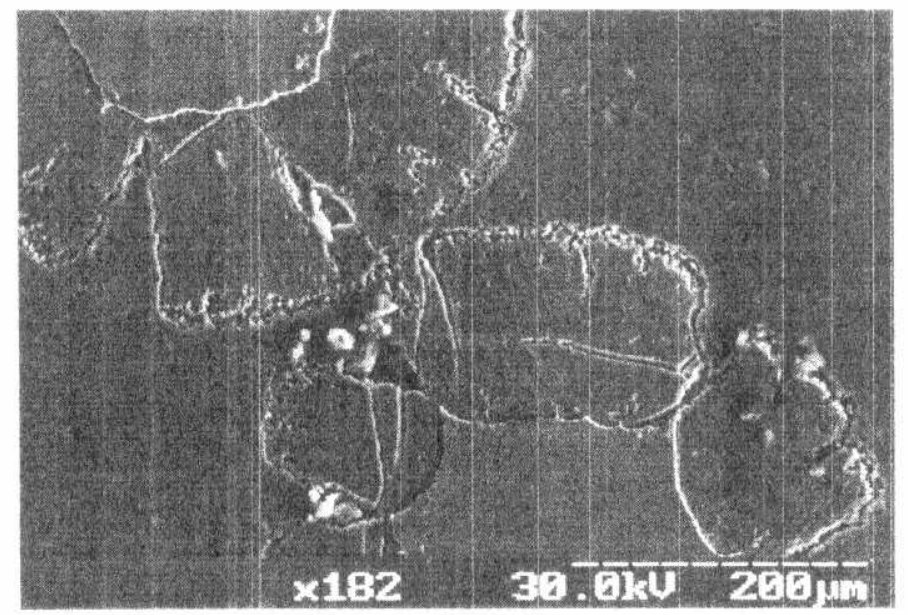

Figure 2c: Scanning Electron Microscopy of Aluminum Metal Matrix Composite Sample With Steel Fibers Produced by Hot Pressing at $630^{\circ} \mathrm{C}$ for Three hours. 


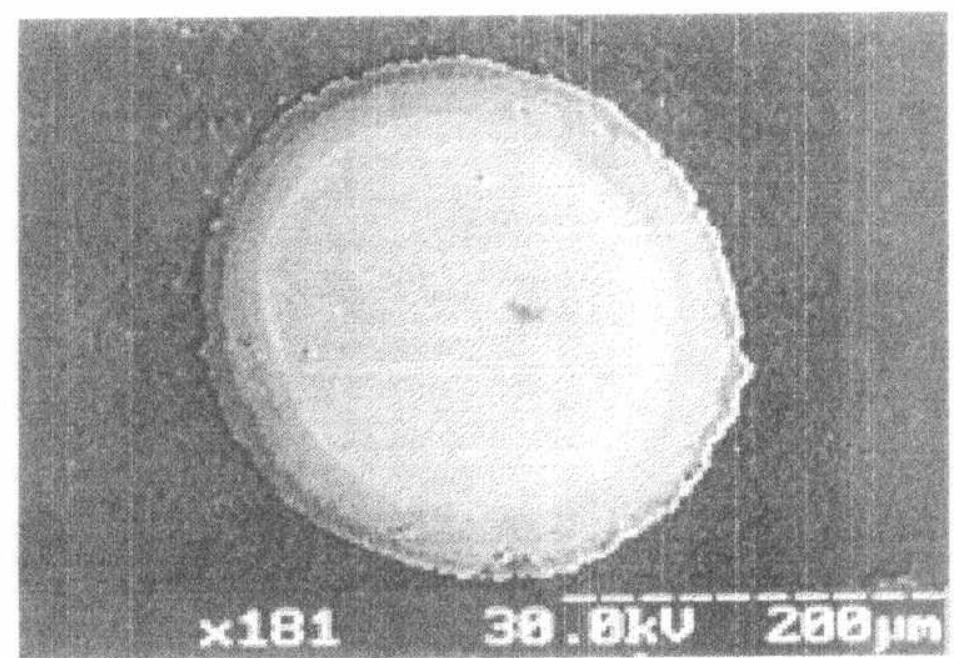

Figure 3a: Scanning Electron Microscopy of Aluminum Metal Matrix Composite Sample With Steel Fibers Produced by Hot Pressing at $640^{\circ} \mathrm{C}$ for one hour.

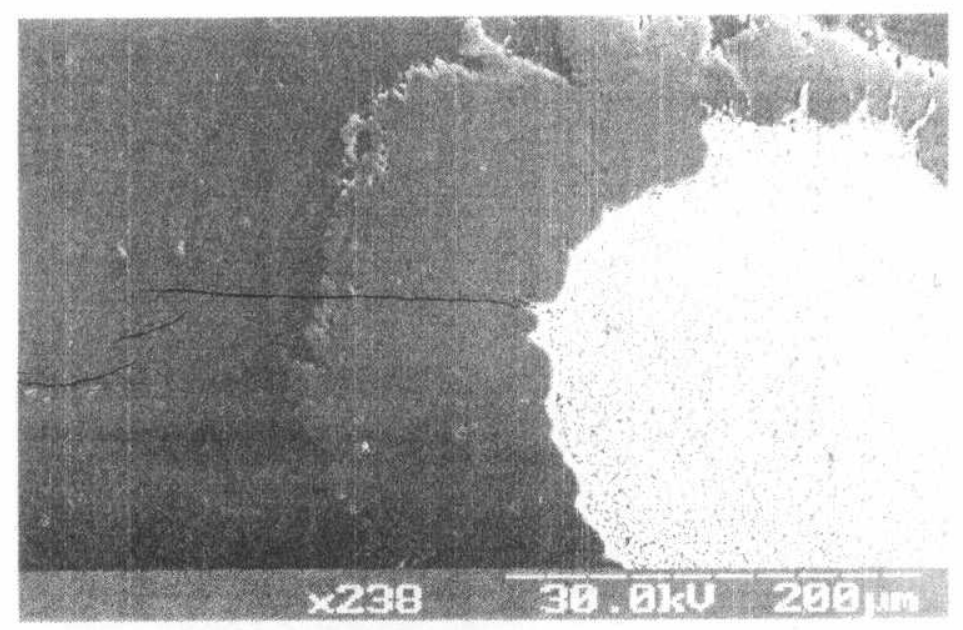

Figure 3b: Scanning Electron Microscopy of Aluminum Metal Matrix Composite Sample With Steel Fibers Produced by Hot Pressing at $640^{\circ} \mathrm{C}$ for Two hours

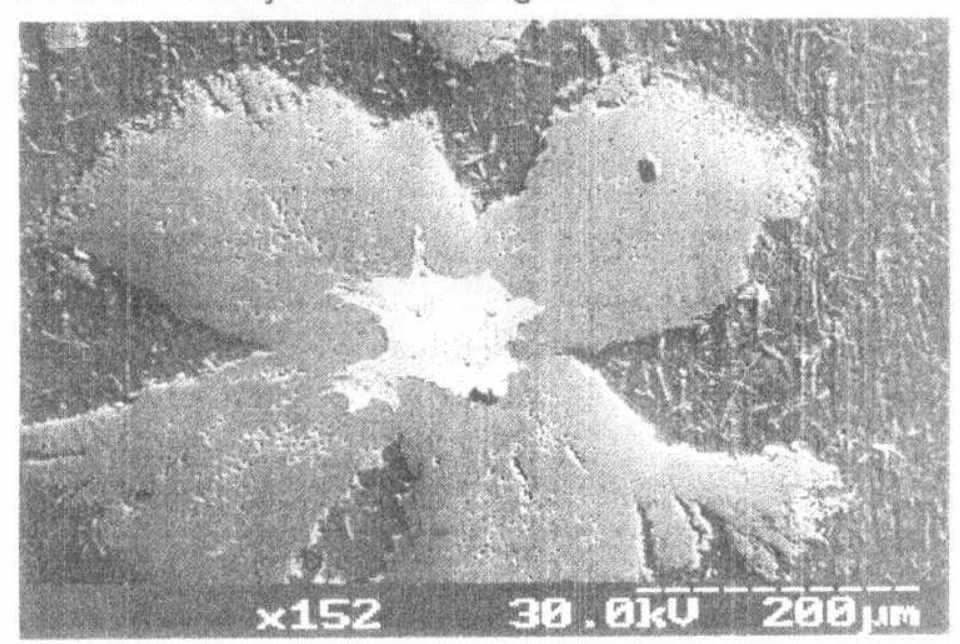

Figure 3c: Scanning Electron Microscopy of Aluminum Metal Matrix Composite Sample With Steel Fibers Produced by Hot Pressing at $640^{\circ} \mathrm{C}$ for Three hours 


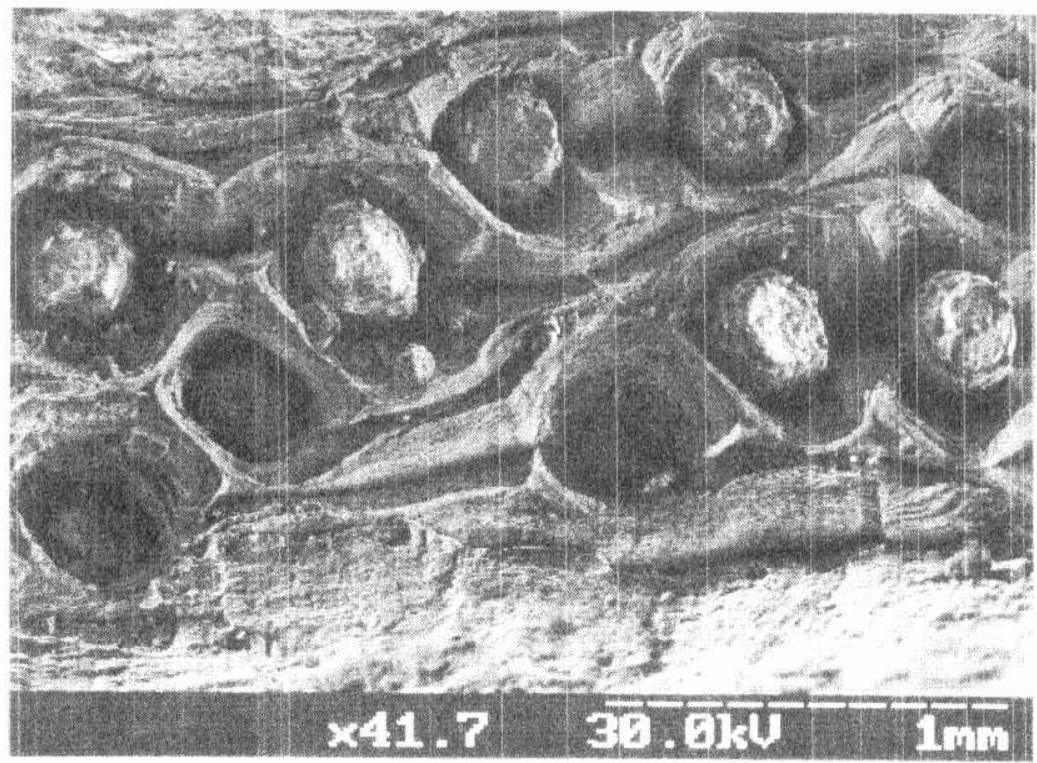

Figure $4 \mathrm{a}$ : Fracture Surface of Aluminum Metal Matrix Composite Sample With Steel Fibers Froduced by Hot Pressing at $630^{\circ} \mathrm{C}$ for Two hours (Delamination and Fiber PuilOut)

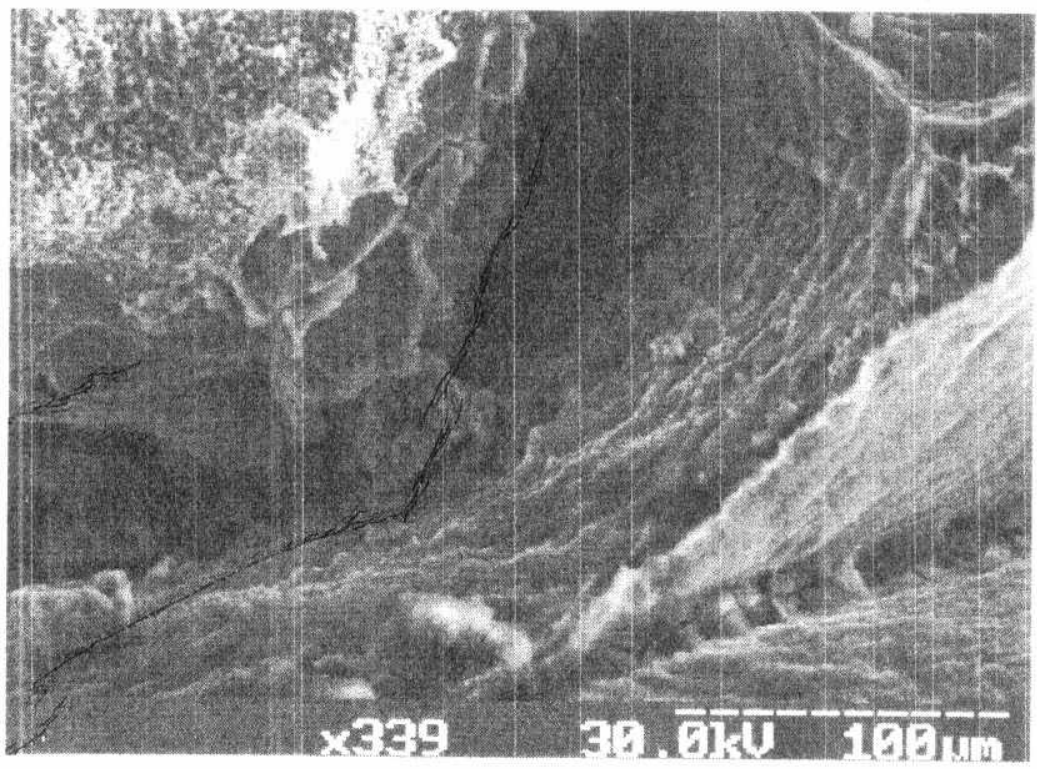

Figure 4b: Ductile Dimpled Fracture Surface of Aluminum Metal Matrix Composite Sample With Steel Fibers Froduced by Hot Pressing at $640^{\circ} \mathrm{C}$ for one hour (High Mag.). 


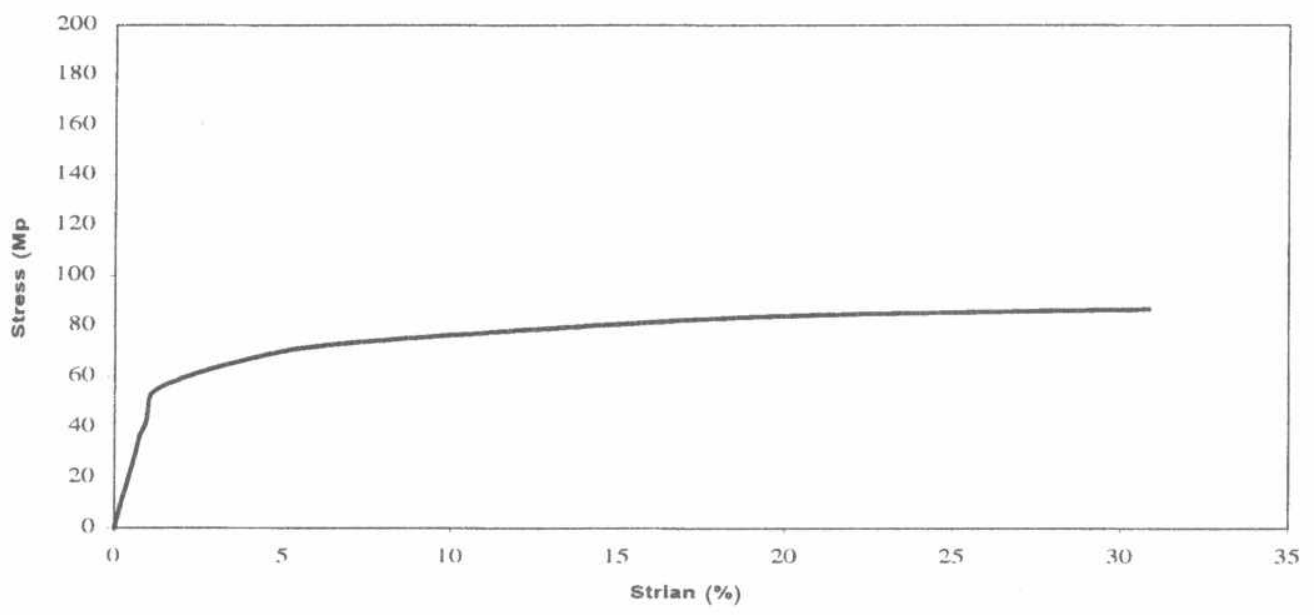

(a)

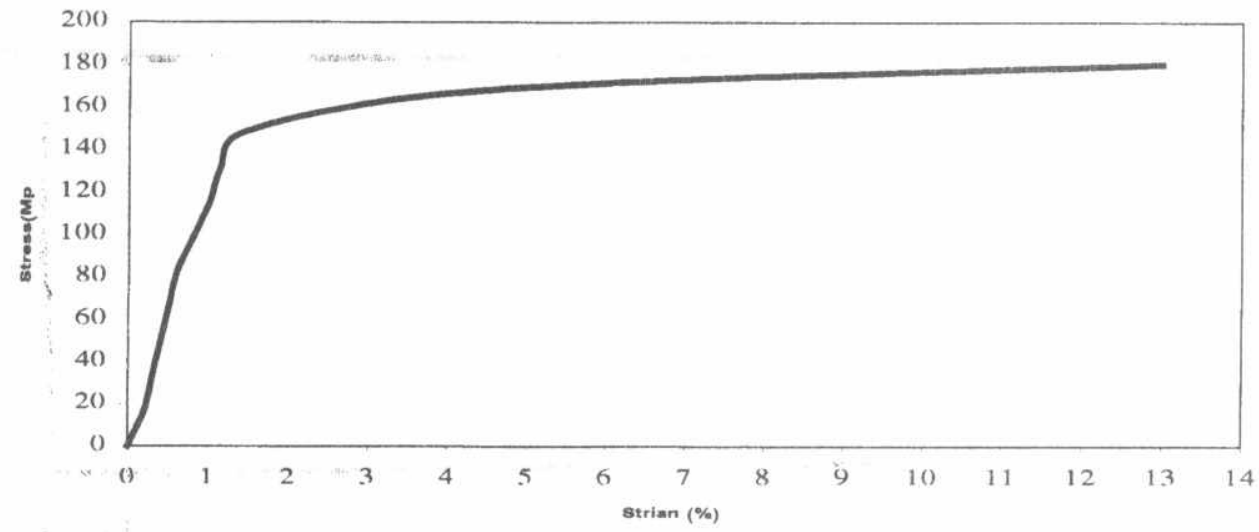

(b)

Figure 5a-b: Stress-Strain Diagram of (a) Monolithic Matrix of Aluminum Compared To (b) Hot Pressed Al-MMC Reinforced with Steel Fibers (300 $640^{\circ} \mathrm{C}$ for One Hour. 


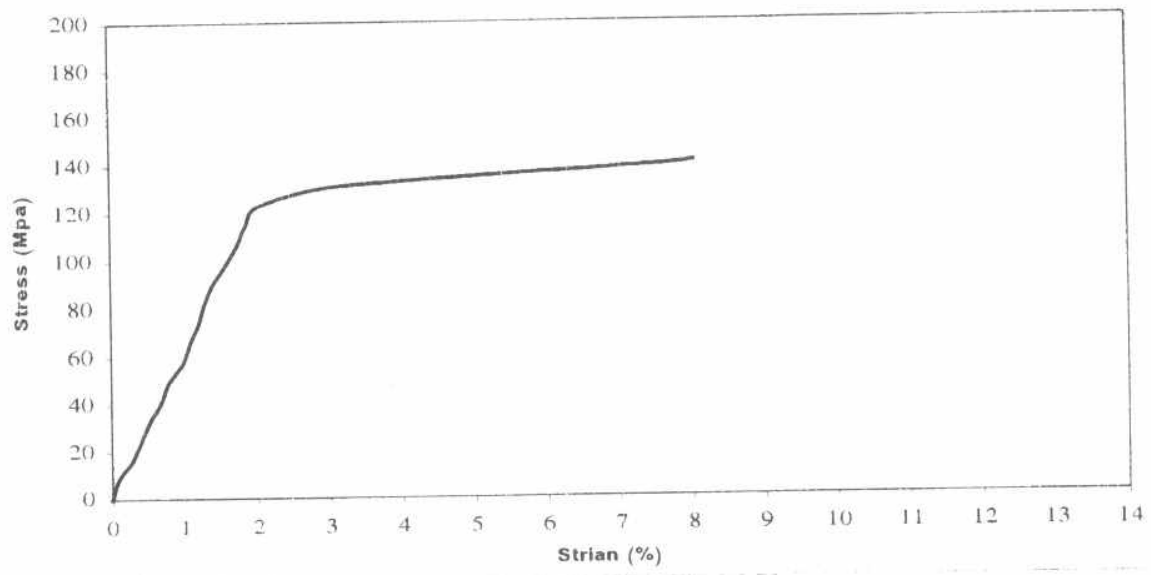

(c)

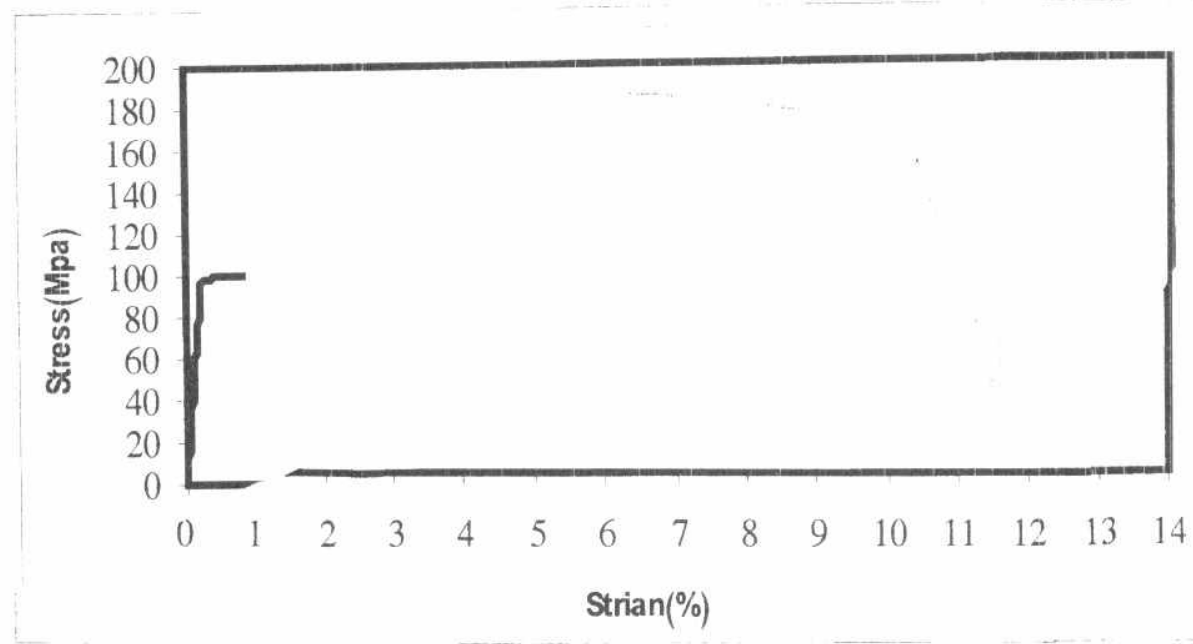

(d)

Figure 5c,d: Stress-Strain Diagram of Hot Pressed Al-MMC Reinforced with Steel Fibers $(300 \mu \mathrm{m})$ HIPed at $640^{\circ} \mathrm{C}$ for (c) Two Hours, and (d) Three Hours. 